\title{
Therapeutic potential of curcumin against lead-induced toxicity: A review
}

\author{
Abubakar Kabeer ${ }^{1,2}{ }^{\oplus}$, Maryam Muhammad Mailafiya ${ }^{1,2}$, Abubakar Danmaigoro ${ }^{3}$, Ezamin Abdul Rahim ${ }^{1, *}$, \\ Md Zuki Abu Bakar ${ }^{4}$
}

\author{
${ }^{1}$ Department of Medical Imaging, \\ Faculty of Medicine and Health Sciences, \\ Universiti Putra Malaysia
}

${ }^{2}$ Department of Anatomy, College of Medical Sciences, Federal University Lafia

${ }^{3}$ Department of Veterinary Anatomy, Usman Danfodio University Sokoto-Nigeria

${ }^{4}$ Department of Veterinary Anatomy, Faculty of Veterinary Medicine, Universiti Putra Malaysia

\section{Correspondence}

Ezamin Abdul Rahim, Department of Medical Imaging, Faculty of Medicine and Health Sciences, Universiti Putra Malaysia

Email: ezamin@upm.edu.my

History

- Received: Dec 20, 2018

- Accepted: Feb 21, 2019

- Published: March 31, 2019

DOI :

https://doi.org/10.15419/bmrat.v6i3.528

\section{Check for updates}

\section{Copyright}

(C) Biomedpress. This is an openaccess article distributed under the terms of the Creative Commons Attribution 4.0 International license.

\begin{abstract}
Lead poisoning causes numerous clinical implications in almost all organs, with the brain, liver, and kidneys serving as the primary targets due to the abundant presence of mitochondria. Curcumin is one of the most potent constituents of Curcuma longa, which is lipophilic, phenolic and water insoluble. Curcumin is a strong antioxidant and anti-inflammatory agent in the treatments of neurodegenerative disease, cardiovascular, renal, and liver diseases, with a potential anticancer mechanism in a few clinical and experimental trials. This review will focus on the health impact of lead-induced toxicity in different organ-systems, which occurs as result of increased oxidative stress through the generation of reactive oxygen species (ROS) and reactive nitrogen species (RNS) and will discuss the therapeutic potential of curcumin against lead-induced toxicity in both human and animals.

Key words: Anti-inflammatory, Antioxidant, Curcumin, Lead-induced toxicity, Oxidative stress, Reactive oxygen species
\end{abstract}

\section{INTRODUCTION}

Lead toxicity is a common public health threat in developing countries due to human activities such as mining and farming ${ }^{1}$. Lead is a multi-organ toxicant involved in various cancers, neuronal and renal damages and reproductive impairments in both human and animals, which can eventually causes death in young children ${ }^{1,2}$. Although several occupational and public health safety measures have been carried out to reduce the cases of lead exposure to the minimal level, yet, several cases of lead poisoning are still recorded.

The application of standard drugs such as chelators in the treatment and management of heavy metal poisoning have been documented to show numerous side effects ranging from mild to severe levels, which may include fever, headache, nausea and vomiting, seizures, brain damage, anemia, permanent kidney and liver diseases, low blood pressure, and severe allergic reactions such as anaphylactic shock. Only a few local herbs extracts have been shown to provide positive effects against lead mediated injury both in in vitro and in vivo studies ${ }^{1}$.

Curcumin has anti-inflammatory and antioxidant properties with a wide range of therapeutic potentials both in vitro and in vivo ${ }^{3}$, which makes it suitable in reversing the biomarkers and alterations induced by lead toxicity in several organs due to induction of oxidative stress (OS) through generation of reactive oxygen species (ROS) and stimulation of inflammatory response ${ }^{4,5}$. This review will focus on the therapeutic potential of curcumin against lead-induced toxicity in both human and animals.

\section{Epidemiology of Lead Toxicity}

According to World Health Organization (WHO) survey about $0.6 \%$ of global heath threatening diseases and 600,000 sources of intellectual impairment among children are attributed by lead poisoning 6,7 . WHO and United State Center for Disease Control and Prevention (CDC) has indicated that a critical level of $10-15 \mu \mathrm{g} / \mathrm{dL}$ of lead in the blood can be considered as an elevated blood lead level ${ }^{8,9}$.

Blood lead levels in the pediatric population have decline dramatically since 1970 s as a result of public health policies such as removal of lead in paints, gasoline, and other consumer products ${ }^{10}$. However, based on National Health and Nutrition Examination (NHANES) survey from 2007 to 2010, children between the age of 1 to 5 years with blood lead levels (BLLs) exceeding $5 \mu \mathrm{g} / \mathrm{dL}$ accounted for approximately $2.6 \%$ with 535000 children ${ }^{11}$. In addition, socioeconomic status plays an important role in mean blood lead levels (BLLs) in younger children, however, the greater risk is attributed to non-Hispanic black population ${ }^{10-12}$. 
Occupational exposure to lead is associated with numerous health implications such as, cancer and mortality. Even at a low concentration in adults, lead can results in different adverse health challenges, which may include cognitive impairments, reproductive effects and hypertension ${ }^{13,14}$.

According to the United State Occupational Safety and Health Administration (OSHA) report, an estimated population of 804,000 within the general industry workers and 838,000 among construction industry workers are prone to lead exposure due to the nature of their occupations. Data from the Adults Blood Lead Epidemiology and Surveillance (ABLES) program revealed a significant reduction in elevated blood lead levels (BLLs) prevalence among adults, thus occupational exposure remains a public health concern with approximately $94 \%$ of industrial workers exposed to lead ${ }^{2}$.

Lead $(\mathrm{Pb})$ is a naturally occurring soft, moldable, and blue-gray heavy metal with relatively low melting point which is found in combination with other elements in our environment. It is considered as the major pollutant of the environment due to its popular use in product manufacture (Figure 1) such as paints, gasoline, batteries, cosmetic products, water pipes, tank linking, poetry glazing and toys ${ }^{7,15}$. In addition, exposure to lead in the environment can caused damage to several biological systems, which can occur from several sources such as air, water, food and other consumer products ${ }^{10}$. Ingestion and inhalation of lead particles are the primary modes of exposure in the environment, while skin and prenatal exposure has been reported in few cases ${ }^{10,16}$.

Nevertheless, lead exists in two (2) different forms, organic and inorganic lead ${ }^{16}$. Organic lead (tetraethyl and tetra methyl lead) is used as a fuel additive to increase octane rating in the past. However, organic lead exposure is considered as an occupational exposure and is tremendously hazardous because it can penetrates the skin before being absorbed by the body, which results in extreme toxicity to the central nervous system when compared to inorganic lead ${ }^{7}$. In contrast, inorganic lead is found in consumer products such as paint and toys, and other environmental content such as soil, and dust ${ }^{7,17}$.

Lead and other heavy metals are found in combination with other element in a relatively low pollutant concentrations in all parts of the environment, hence, the presence of lead in the environment has no role to play in the physiological system and this can lead to an irreversible health effects with a lot of morbidity such as hepatic, nervous and renal system disorder ${ }^{18,19}$. Moreover, due to human activities such as farming and mining concentration of these heavy metals have increased drastically in the environment, particularly in areas where the metals are mined and processed for industrial use ${ }^{16,20,21}$.

\section{Pathophysiology of Lead Toxicity Absorption of Lead}

Gastrointestinal and inhalational absorption of lead is the most common route of absorption of lead particles. However, dermal absorption is a form of absorption route for organic lead although it is considered insignificant, and only account for less than $1 \%$ of lead absorbed in the body system ${ }^{22}$.

Papa Nikolaou et al. ${ }^{23}$ reported that gastrointestinal absorption rate of lead is correlated to sociodemography of the exposed individual. In addition, children absorbed almost $50 \%$ of lead compared with $15 \%$ in adults due to their pica behavior (Figure 2). However, when lead is absorbed it accumulates in blood, soft tissues, and bones ${ }^{1,24,25}$.

Nevertheless, approximately $100 \%$ of fine particles of lead inhaled as fume or vapor may be absorbed by the lungs directly or transported by the mucociliary tree to the esophagus where it may be swallowed and absorbed through the gastrointestinal tract. The absorption of lead depends on the particular nature of the toxicant, volume of the respiratory tract and mucociliary clearance of the toxicant ${ }^{22}$.

\section{Distribution of Lead}

Lead concentration in the plasma is the most important means of distribution of lead to target organs such as the brain, kidney, liver, spleen, bones, aorta and teeth, which accounts for only $1 \%$ of the total lead concentration in the blood, leaving $99 \%$ concentration in the erythrocytes ${ }^{1,10,23,26}$. Furthermore, lead distribution to the entire body depends on the systemic blood flow and soluble phosphate, which harbors more than $95 \%$ of lead deposited into the skeletal bones (Figure 2) ${ }^{7,12,27}$. Nevertheless, bone contaminated with lead in adult accounts for about $80-95 \%$ of the total health burden, which is higher than in children with about $70-73 \%{ }^{12}$.

In addition, an estimated half-life of lead in adults blood is 30-40 days and is longer in children and pregnant women ${ }^{10,12,25}$. Moreover, lead in the liver interfere with the cytochrome P450 enzymes, which affects hormone synthesis, and cholesterol synthesis ${ }^{10}$. In adults and children about $94 \%-70 \%$ of lead is accumulated in the bones where it is tightly bounded and is less harmful ${ }^{25}$. 


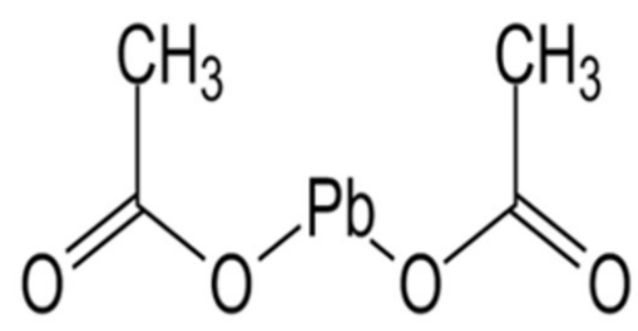

Figure 1: Chemical Structure of Lead Acetate.

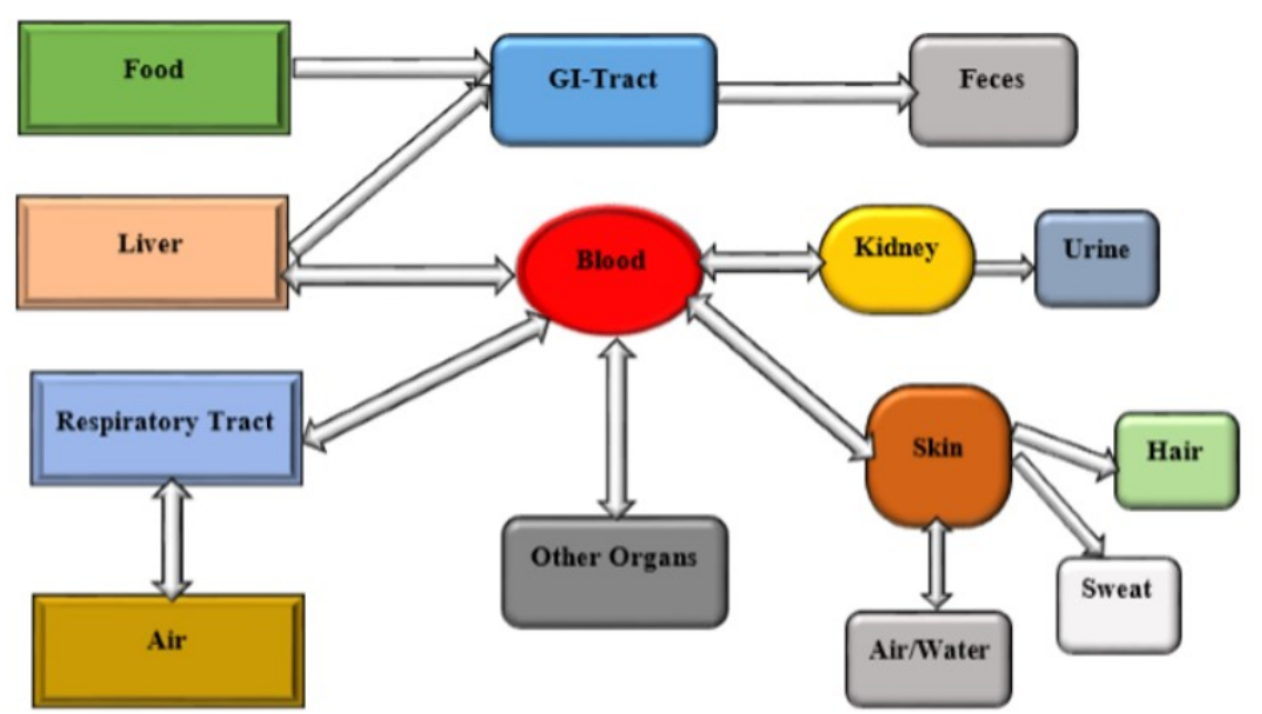

Figure 2: Pathophysiology of Lead toxicity: The absorption, distribution of lead through plasma and excretory fate of lead in the body after exposure.

\section{Excretion}

Lead absorbed in the body are not easily metabolized, therefore the excretion is low and the excretion route is mostly through the urinary tract. In addition, chelating agent can facilitate the excretion of lead from the body via urine ${ }^{12,23}$. Little amounts of lead are excreted through the gastrointestinal tract, sweat and nails, thus these routes are considered as insignificant $^{12}$.

\section{General Symptoms of Lead Toxicity}

Clinical symptoms of lead toxicity are asymptomatic or nonspecific and are dependents on the duration and levels of exposure. However, the symptoms can be classified into two categories, which could be ei- ther acute or chronic clinical symptoms ${ }^{1,7,9,28}$. The symptoms of acute toxicity includes muscle pain, fatigue, abdominal pain, headache, vomiting, seizures and coma. Clinical symptoms of chronic toxicity includes persistent vomiting, encephalopathy, lethargy, delirium, convulsions and coma ${ }^{1,28,29}$.

\section{Mechanism and Toxicological Profile of Lead-induce Toxicity}

Pathogenesis of lead is due to its ability to bind to proteins group sulfhydryl, resulting to toxicity of multiple enzyme systems. Calcium-activated proteins binds to lead in a greater affinity than to calcium, hence hindering cellular physiology ${ }^{10,25,30}$. Upturn in metabolic rate results in over-production of free 
radicals, which in turn leads to oxidative stress damage such as lipid peroxidation, damage to proteins and nucleic acids and distortion of normal physiology in tissues $^{31}$. Oxidative stress is a major biomarker in the development of several disorders in disease manifestation such as diabetes, chronic kidney disease, hepatic inflammation, chronic cardiac disease, neurodegenerative diseases and others ${ }^{32}$.

However, at the molecular level it is difficult to limit lead toxicity on cellular damage ${ }^{33}$. The enzymatic functions of proteins and other cellular activities are affected by the presence of lead in the system ${ }^{30}$. In addition, the induction of oxidative stress and damage of nucleic acids are other mechanisms of lead toxicity and exposure, which can result in several clinical symptoms of toxicity. Hence, the magnitude of exposure and cell types depends on the mechanism of toxicity and the levels of lead exposure (Figure 3) ${ }^{33-35}$.

\section{Oxidative Stress}

Increased levels of reactive oxygen species (ROS) are the major toxic effects of lead ${ }^{1}$. Reactive oxygen species are by-products of biochemical processes in aerobic organisms and ROS concentration is regulated by the activity of antioxidant enzymes such as glutathione $(\mathrm{GSH})$, super oxide dismutase (SOD), glutathione peroxidase (GPx), and catalase (CAT) under normal conditions ${ }^{12}$. The imbalance between the production and scavenging of ROS results to oxidative stress, which could lead to ROS detoxification system impairment and increased production of $\operatorname{ROS}^{1,33,34}$. However, during oxidative stress, overproduction of free radicals results in negative effects on cells, tissues, inflammatory responses, and apoptosis ${ }^{1,12,33}$. Neurodegenerative diseases such as Alzheimer's and Parkinson's disease are the primary results of increased production of ROS in the body system ${ }^{36}$.

Glutathione (GSH) is a tripeptide with a sulfhydryl group and is the most important antioxidant found in mammalian cells in millimolar concentrations. GSH is vital in the scavenging of free radicals and can exist in either reduced (GSH) or oxidized (GSSG) forms. However, $90 \%$ of glutathione under normal circumstances are in a reduced form (GSH). In abnormal condition of oxidative stress, glutathione concentration in oxidized form (GSSG) is in abundant compared to $\mathrm{GSH}^{1}$.

Super oxide dismutase (SOD) and catalase (CAT) are notable antioxidant enzymes that are essential in rendering lead inactivation in the system. However, the impairment in superoxide radicals $\left(\mathrm{O}_{2}{ }^{-}\right)$scavenging is a direct consequence of reduced CAT concentration in the serum decrease SOD concentration, which results in reduced disposal of superoxide radicals ${ }^{1}$. In addition, lead has the ability to replace zinc ions which are an important factors in deactivating the antioxidant defense mechanism beside targeting sulfhydryl groups ${ }^{1,37}$.

Another important oxidative stress biomarker associated with lead toxicity is lipid peroxidation, which accounts for increased reactive oxygen species (ROS) on lipid membrane, thus damaging the cells ${ }^{1}$.

Oxidation of hemoglobin is attributed to lead toxicity, leading to red blood cell (RBC) destruction through the inhibition of Delta-aminolevulinic acid dehydrates (ALAD) and increased substrate alphaLinolenic acid (ALA) concentrations in urine and blood. Furthermore, increased in ALA levels produce superoxide and peroxide radical that interfere with oxyhemoglobin consequently leading to hydroxyl radicals generation, which in turn put the cells at risk of oxidative stress and apoptosis ${ }^{38}$.

\section{Ionic Mechanism}

The ability of lead as a divalent cation to substitute bivalent $\left(\mathrm{Ca}^{2+}, \mathrm{Mg}^{2+}, \mathrm{Fe}^{2+}\right)$ and monovalent $\left(\mathrm{Na}^{+}\right)$ cations results in the impairment of several important biological processes in the system. This ability to substitute both bivalent and monovalent cations, especially the bivalent cations is termed the ionic mechanism of lead toxicity ${ }^{1,7,39}$.

Neurological deficits are associated with the ionic mechanism of lead toxicity due to the ability of lead to replace calcium ions ${ }^{12}$. Therefore, lead molecules become competent and subsequently cross the blood brain barrier (BBB) at a significant rate, where they accumulate in the astroglial cells. Moreover, developing nervous system contain numerous immature astroglial cells, which become more prone to toxic effects of lead due to the lack of lead binding proteins in the immature astroglial cells ${ }^{12,40}$.

The concentration of lead even in a pico molar, has the ability to replace calcium, and affect vital neurotransmitters such as protein kinase $\mathrm{C}$, which regulates memory storage and neural excitation. In addition, sodium ions concentration is also affected by lead toxicity resulting in several neuronal signaling impairments due to misbalancing of neurotransmitters ${ }^{1}$. Other deleterious effects of ionic mechanism of leadinduced toxicity on different fundamental biological cellular processes include, cell adhesion, protein folding and maturation, intra and inter cellular signaling, neurotransmitters release, enzyme regulation, ionic transportation, and apoptosis ${ }^{1,40}$. 


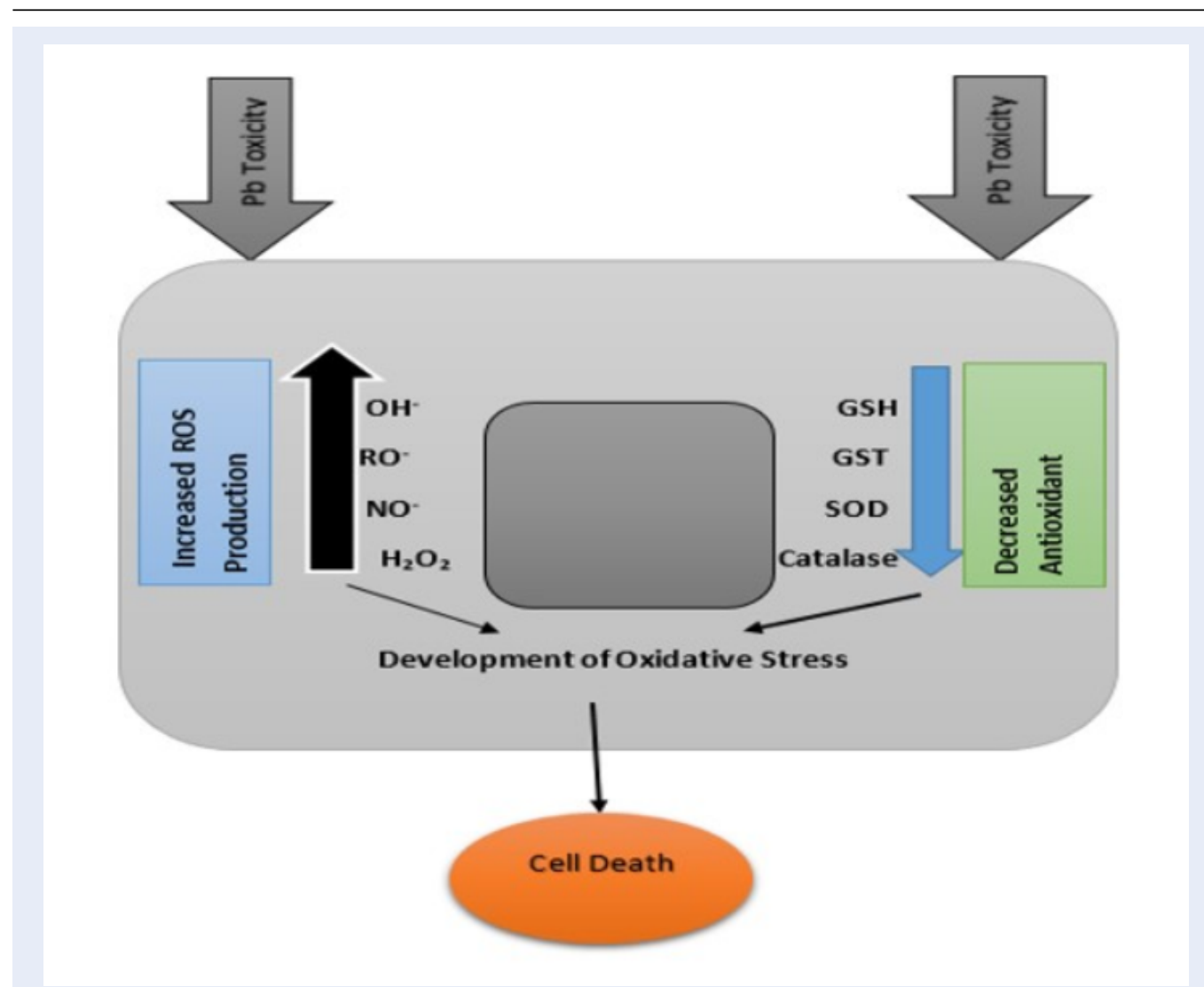

Figure 3: Schematic representation of lead induced toxicity: Lead exposure increases generation of ROS and decreases the levels of antioxidants, leading to oxidative stress and subsequent apoptosis.

\section{Effects of Lead Toxicity Nervous System}

Lead-induced neurotoxicity mechanisms are composite and include membrane bio-physics alteration, deregulation of cell signaling, oxidative stress and impairment of neurotransmitter transmission. Furthermore, lead absorption rate through the gastrointestinal tract relies on the physicochemical and individual characteristics of the materials ingested ${ }^{12}$.

Lead toxicity interferes with glial cells interaction, trimming and pruning of synapses, and neuronal migration during brain development, which lead to failure in creating a proper link between different brain structures and subsequently resulting to permanent alteration of brain physiology ${ }^{15,41}$.

Lead toxicity is multi-systemic with high affinity and severity on the central nervous system (CNS) by blocking N-methyl-D aspartate receptors that aid in the maturation of brain, flexibility, and memory storage. This result to the interruption in long-term storage of memory and other cognitive behaviors. In addition, elevated blood lead levels is pivotal in disrupt- ing the integrity of the blood-brain barrier ${ }^{30}$.

Exposure to high levels of lead concentration in the blood-brain barrier results in the movement of plasma into the brain interstitial space, subsequently leading to encephalopathy of the brain and edema of the cerebellum ${ }^{30}$. At the blood lead levels of (BLLs) $10 \mu \mathrm{g} / \mathrm{dL}$, extreme increase in pressure is caused by edema in the brain, which results in irreversible brain destruction and alteration including impaired visual-motor skill, reduced attention, decreased social behavior and decline in cognitive ability ${ }^{30,41}$.

\section{Renal System}

Kidney remains a vital organ of target upon cumulative exposure to lead both environmentally or occupationally, which may cause acute or chronic nephropathy with several health implications such as deficit in tubular transport mechanism (tubular absorption and reabsorption), degenerative changes in tubular epithelium, renal dysfunction, renal failure, hypertension, and hyperuricemia ${ }^{42}$. In comparison, acute $\mathrm{Pb}$ nephropathy effects are reversible in children mani- 
festing glycosuria and aminoaciduria by using chelation therapy, while chronic $\mathrm{Pb}$ nephropathy is irreversible that develops over a long period of time due to prolonged exposure ${ }^{43,44}$.

The results obtained by Mao et al., ${ }^{45}$, suggested that lead selenide nanoparticles induction of oxidative damage in Sprague-Dawley rats showed histopathological changes in kidney such as, foci of ischemia and clogged blood vessels, interstitial fibrosis, raise in number of fibroblasts and severe renal parenchymal destruction.

\section{Bones}

Bones remain the primary site for storage of lead in the human body after exposure ${ }^{46}$. Once lead is absorbed, it moves into the bloodstream where it is primarily circulated to the soft tissues through plasma (kidney, liver, and brain), blood and mineralized tissues such as the bones. Then it exerts more toxic effects by binding to the cell membrane, damaging protein architectural structure, and meddling with gene interpretation in the body ${ }^{18,47}$.

Lead deposited in the bone have an estimated halflife of 20-30 years. However, bone metabolism and activities results in the discharge of lead back into the bloodstream, thus, blood lead level (BLLs) is increased, which in turn have detrimental effects in pregnancy, lactation, and menopause ${ }^{41}$.

Moreover, methodology such as stable lead isotope revealed that an estimated $40-70 \%$ of lead is released from the blood to bones in adults, hence, adults bones store $85-95 \%$ of lead but children only store $70 \%$ of lead in the bones and greater absorption of lead is in the soft tissues ${ }^{1}$. The rate of exposure, age, pregnancy, race and gestation are factors that affect storage and mobilization of lead in bones ${ }^{1}$.

\section{Reproductive System}

Exposure to lead have numerous effects on the reproductive system both in human and animals which includes reduced libido, abnormal spermatogensis, infertility, changes in serum testosterone, abnormal prostatic function, miscarriage, pre-eclampsia, premature delivery, and premature membrane rupture in both males and females ${ }^{1}$.

Previous studies indicated that lead could cause peritubular testicular fibrosis, reduced sperm number, disrupted regulation of luteinizing hormone, lower testosterone synthesis, distraction of preantral follicles and increased atresia in ovaries, and reduced number of primordial follicles in female pups in rodents $^{48,49}$.

\section{Cardiovascular System}

Lead exposure associated with cardiovascular effects is not restricted to amplified blood pressure and hypertension but is rather associated with other deleterious cardiovascular clinical burdens such as stroke, peripheral arterial diseases (arteriosclerosis and atherosclerosis), and coronary heart diseases which have underlying cardiovascular malfunctioning and abnormalities such as alterations in cardiac rhythmicity and left ventricular hypertrophy ${ }^{49}$.

\section{Hematological Parameters}

The total body burden of blood lead represents merely $1-5 \%$, however, $95-99 \%$ concentration of blood lead at lower concentrations binds to red blood cells (RBCs) with an estimated $1 \%$ in the plasma in an ionized form. Lead binding sites in the red blood cells (RBCs) can become saturated at higher concentrations, resulting in more lead presence in the plasma ${ }^{47}$.

Destruction of Red Blood Cells (RBCs), and alteration in heme synthesis is associated with lead toxicity, however, hemoglobin production decreases when heme biosynthesis is altered due to lead toxicity at the blood lead levels (BLLs) of $401 \mathrm{~g} / \mathrm{dL}^{10,50}$. Moreover, lead toxicity inhibits heme synthesis by impeding the actions of $\delta$-aminolevulinic acid dehydratase (ALAD), ferrochelatase, aminolevulinic acid synthatase (ALAS), aminolevulinic acid (ALA) and other mitochondria enzymes, which reduce the life span of erythrocytes in circulation due to persistent instability of the cell membrane, and lead to ane$\operatorname{mia}^{1,51}$.

Moreover, hemolytic (acute exposure) and Frank (chronic exposure) anemia are the direct consequence of lead poisoning ${ }^{1}$.

Lead toxicity causes anemia in young and iron deficient children, which is correlated with blood lead concentration (BLLs). In addition, lead toxicity results in clinical alteration of heme-biosynthesis and increased red blood cell destruction ${ }^{7,51}$.

Alwaleedi ${ }^{51}$ induced lead toxicity in white wool albino mice using different concentrations, of $0.4,0.8$, and $1.2 \mathrm{mg} / \mathrm{kg}$ orally within 12 weeks which resulted in hematological and tissue morphological alteration. Importantly, lead toxicity has several effects on the biological system and it is considered as the major cause of physiological, biochemical, hematological, and morphological alterations. Even at low concentrations, treatments with lead acetate have an adverse effect on health in animals. Therefore, it is important to prevent exposure to lead in the environment ${ }^{52}$. 


\section{Spleen}

The work of Ekanem et al. ${ }^{18}$ showed an evidence of lymphoid follicles hyperplasia within the white pulp with congested blood vessels and alteration in hematological profiles within the spleen which occurred upon lead-induced toxicity in Albino rats treated with different concentrations of lead acetate.

The works of Türkay et al. ${ }^{51}$ revealed ultra-structural alterations on spleen with macrophage and lymphocyte infiltration, vacuolation of cytoplasm, erythrocyte stasis, swollen mitochondria with cristae loss in lymphoid cells, and degeneration of spleen cells.

\section{CURCUMIN AND ITS CURATIVE POTENTIAL MECHANISM}

Curcumin (1,7-bis[4-hydroxy-3-methoxyphenyl]1,6-heptadiene-3,5-dione) is a yellow color compound that is lipophilic, phenolic, water insoluble and is a derivative of the rhizomes of turmeric (curcuma longa). Curcumin is a member of the ginger family (Zingiberaceae) that is widely considered as a traditional medicine and food additive in Asia (Figure 4) ${ }^{53-55}$. Curcumin is the most biologically active constituent of Curcuma longa and it is readily available commercially as a mixture of 3 curcuminoids (95\% curcumin). However, this mixture of the 3 curcuminoids classically contains $77 \%$ curcumin, $17 \%$ demethoxycurcumin, and bisdemethoxycurcumin $6 \%$ responsible for the yellow color characteristics of turmeric ${ }^{54,56}$.

Structurally, curcumin can exists in either $\beta$-diketone (CurK) or $\beta$-keto-enol (CurE) tautomers, with the higher antioxidant activity and stability in $\beta$-ketoenol tautomers (CurE) when compared to the $\beta$ diketone (CurK) tautomers. In addition, $\beta$-keto-enol tautomer has triple chelation sites for metals, which includes a double phenol group that serves as a possible reactive centers, and the keto-enolic moieties, which can possibly form metal chelates and scavengers for reactive radicals generated by metal ions ${ }^{57}$. Curcumin has a molecular weight of $368.37 \mathrm{~g} / \mathrm{moL}$ and a melting point of $183^{\circ} \mathrm{C}$. Available literatures have shown that curcumin is more stable in cell culture medium or human blood and is unstable at basic pH medium ${ }^{58}$.

In respect to curcumin side effects, approved bodies such as European Food Safety Authority (EFSA), US Food and Drug Administration (FDA), United Nation and World Health Organization Expert Committee on Food Additives reported, that curcumin is Generally Recognized As Safe (GRAS), with the tolerable and safety doses between 4000 and $8000 \mathrm{mg} /$ day $^{59}$.
In concurrence with several literatures, curcumin has been proven to have a wide range of therapeutic effect which include, antioxidant, antibacterial, antifungal, antiviral, antitumor, cancer chemo-preventive, antimalarial, anti-inflammatory and hepatoprotective abilities, and the ability to improve cardiovascular and neurodegenerative disorders ${ }^{57,60-62}$. In addition, curcumin has the ability to easily cross the bloodbrain barrier where it binds to plaques in the brain to inhibit amyloid- $\beta$ peptide aggregation in patient with Alzheimer's disease ${ }^{60,63,64}$.

Despite the therapeutic benefits of curcumin, the major challenge is attributed to its poor bioavailability due to poor absorption, fast metabolism, and rapid elimination from the body by the gastrointestinal tract ${ }^{65}$. Curcumin bioavailability can be enhanced through several agents such as piperine which is an active component of black pepper and its mechanism of action which includes the blocking of the metabolic pathway in order to delay the metabolism of curcumin ${ }^{5}$. In addition, about $2000 \%$ increase in bioavailability of curcumin is associated with the primary active component of black pepper, piperine ${ }^{5,66}$.

\section{Antioxidant Mechanism}

Curcumin alleviates systematic markers of oxidative stress by increasing the activities of serum anti-oxidants enzymes such as superoxide dismutase (SOD), glutathione peroxidase (GSH) and lipid peroxides. Moreover, curcumin antioxidant mechanism is executed in different patterns, which may include free radicals scavenging of reactive nitrogen species (RNS) and reactive oxygen species (ROS) as well as increasing the activity of serum enzymes such as GSH, catalase, and SOD that could result in the activation of inflammatory responses ${ }^{5}$ (Figure 5).

Moreover, curcumin phenolic antioxidants activity is mainly dependent on electron donation, and although curcumin is hydrophobic, but can be liquefied in ethanol, acetone, and dimethylsulphoxide ${ }^{67}$.

Noteworthy, curcumin, as a lipophilic compound, acts similarly vitamin $\mathrm{E}$ to efficiently scavenge peroxyl radicals and is referred to as a chain breaking antioxidant. Furthermore, curcumin inhibits the activity of ROS-generating enzymes such as xanthine hydrogenase/oxidase and lipoxygenase/cyclooxygenase, which is essential in the down regulation of oxidative stress $^{5,68}$.

\section{Anti-inflammatory Mechanism}

Previous research has shown that curcumin as a polyphenolic compound, interact with several targets that are involved is inflammation. Curcumin 


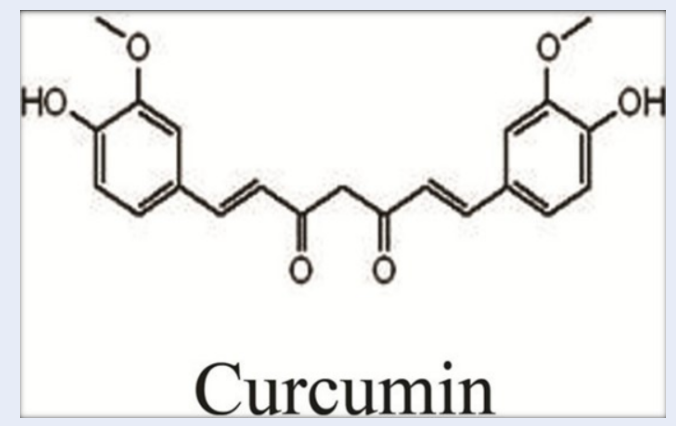

Figure 4: Chemical structure of curcumin.

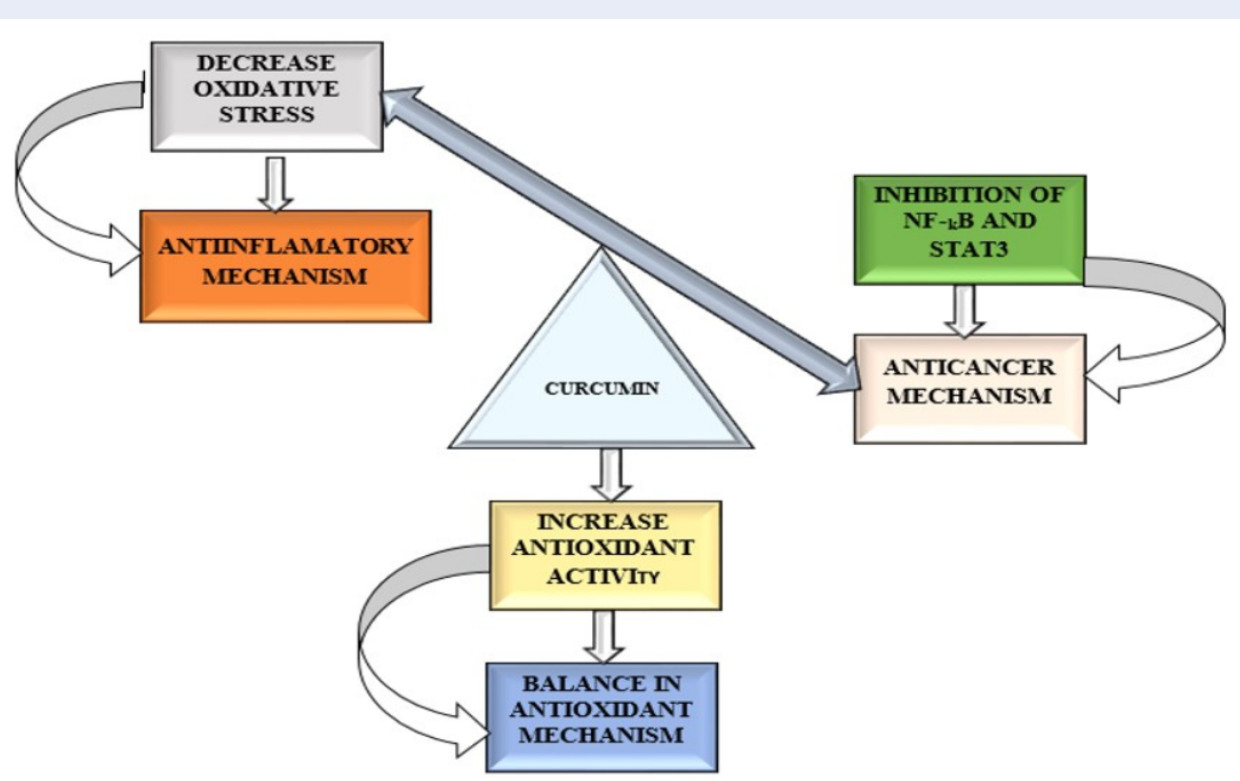

Figure 5: Schematic representation of mechanism of action of curcumin: Curcumin exerts its therapeutic effects by attenuating oxidative stress and inflammation as well as ameliorates cancer via inhibition of NF${ }_{k}$ B and STAT.

moderates inflammatory response by suppressing the activity of cyclooxygenase-2 (COX-2), inducible nitric oxide synthase (iNOS) and lipoxygenase enzymes as well as inhibiting the production of interleukin $1,2,6,8$ and 12 , inflammatory cytokines tumor necrosis factor-alpha (TNF- $\alpha$ ), monocytes chemoattractant protein (MCP) and the down regulation of Janus and mitogen-activated kinase ${ }^{3,69,70}$.

In vivo studies on inflammatory models showed that curcumin inhibits the metabolism of arachidonic acid and inflammation in the epidermis through the down regulation of lipoxygenase and cyclooxygenase pathways and the reduction in $\mathrm{PGE}_{2}$ inflammatory exudate ${ }^{71,72}$.

In vitro studies revealed that curcumin modulates the stimulation of specific transcription factors such as NF-kB and activating protein-1 (AP-1) in activated alveolar macrophages and monocytes, which subsequently hinders cytokine expression of gene ${ }^{3,69}$.

Curcumin reduces inflammation, modulates mitogen-activated protein kinase (MAPK) pathway signaling and attenuates colitis in experiment models by reduction in $\mathrm{p} 38$ MAPK activation ${ }^{73}$. In addition curcumin has been proven to attenuate neuropathic pain, nerve ischemia, demyelination, and decrease inflammation via subsequent activation of $\mathrm{NF}_{k} \mathrm{~B}$ and phosphorylation inhibition of IKK complex ${ }^{74}$.

However, down-regulation of protein kinase $\mathrm{C}$ could be attributed to another anti-inflammatory mechanism of curcumin via inhibition of cytokine produc- 
tion and blocking of NF-kB activation by numerous inflammatory stimuli ${ }^{5,69}$.

\section{Anticancer Mechanism}

In vitro and in vivo studies revealed that curcumin plays a vital role in anticancer mechanism via the inhibition of nuclear factor (NF) ${ }_{k} \mathrm{~B}$ and signal transducer and activator of transcription 3 (STAT3) pathway signals which are influential in cancer development and proliferation by resisting and inhibiting chemotherapy-induced apoptosis in several cancer cells ${ }^{70,75,76}$

Curcumin has been proposed to induce apoptosis which results in the down regulation of cMET cyclin D1, epidermal growth factor receptor (EGFR), and protein kinase $\mathrm{B}(\mathrm{PKB})$ in tumor cells ${ }^{73}$. Furthermore, curcumin has been proved to stimulate apoptosis and inhibit cell cycle arrest and cell proliferation through the modulation of activation protein 1 (AP1 ), early growth response protein 1 (EGR-1), peroxisome proliferator-activated receptor alpha (PPAR- $\alpha$ ), Beta-catenin and other transcript factors ${ }^{73,75,77}$. Aoki et al. ${ }^{76}$, reported that curcumin treatment can competently suppress malignant glioma cell growth as well as autophagy in U87 AND U373-MG cells in a dose-dependent manner. In addition, lung metastasis of breast cancer cells can be inhibited by curcumin or in mixture with paclitaxel.

Endoplasmic reticulum stress and DNA damage can be induced by curcumin resulting in mitochondrialdependent programed cell death (apoptosis) in human cancer A- 549 cells via the activation of caspase-3, and enhanced hepatocellular carcinoma apoptosis in HCC 55 cells via increase in intracellular utilization of $\mathrm{Ca} 2+$ and the disruption of reactive oxygen species (ROS) in the mitochondria ${ }^{71,74}$.

Curcumin is instrumental in preventing cancer invasion and metastasis via inhibition of focal adhesion kinase (FAK) phosphorylation and improving extracellular matrix components expression. In addition, curcumin is known to increase cell adhesion via stimulation of extracellular matrix mechanisms of fibronectin, laminin and, collagen (I, III, IV, and IX) in a concentration reliant pattern, hence avoiding the migration and detachment of cancer cells ${ }^{75}$.

\section{Curative Evidence of Curcumin In vitro and In vivo Studies \\ Liver and Body Weight}

In the work of Mahmoud et al. ${ }^{62}$ reported that curcumin significantly decreases body weight in curcumin treated group by inhibiting the effect on hep- atic gene expression in carbohydrate binding protein responsive elements and sterol regulatory binding protein elements, which subsequently stimulates the expression of lipogenic genes. In addition, curcumin as a dietary additive, may decrease the circulation of lipid by fatty acid synthase inhibition in adipocytes, leading to the decrease in lipid transportation to the liver, thus, hepatic lipid accumulation is inhibited $^{78-80}$.

The results obtained by Um et al. ${ }^{79}$ revealed that microvesicular and macrovesicular steaosis within hepatic cells could be attenuated by dietary supplementation of curcumin in high fat diet (HFD) induced mice via improved hepatic lipid accumulation, thus, serum lipid profiles and insulin resistance are enhanced.

Moreover, curcumin action significantly reduces white adipose tissue macrophage infiltration, upswings adipose tissue adiponectin production and reduce the activity of hepatic $\mathrm{NF}_{-} \mathrm{B}$, hepatomegaly, and inflammation of the hepatocytes ${ }^{62,81,82}$.

\section{Nervous System}

Neuroprotective mechanism against neurodegenerative disorders of the brain by curcumin is due to its ability to bind redox-active metal ions such as $\mathrm{Mn}^{2+}$, $\mathrm{Cu}^{2+}, \mathrm{Cd}^{2+}, \mathrm{Pb}^{2+}, \mathrm{Hg}^{2+}$ to produce a tight and active complex of antioxidant with its anti-inflammatory properties that are essential for the reduction in swelling among neuronal cells within the body ${ }^{57}$.

As reported by Yuan et al. ${ }^{61}$ post-treatment with curcumin in subarachnoid hemorrhage (SAH)induced neurological damage in mice, improves brain functions by inhibiting microglia cells and down-regulating Matrix Metallopeptidase 9 (MMP9), and finally reducing water content in the brain, hence, preserving the integrity of the blood brain barrier (BBB).

Curcumin possesses a robust antioxidant properties such as decreasing the generation of reactive oxygen species (ROS), moderation of antioxidant enzyme concentrations, subduing the peroxidation of lipid and reducing the level of malondialdehyde (MDA). Moreover, curcumin has been proved to decrease plaque pathogenesis by overpowering $\beta$-secretase activity, and eventually hinders oligomer and fibril production ${ }^{60}$.

In a recent work by Shi et al. ${ }^{58}$ it was reported that curcumin could reverse marked apoptosis and restore alteration in key Alzheimer's disease (AD) linked proteins, such as amyloid precursor protein (APP), betaamyloid enzyme 1 (BACE-1), and receptors for advanced glycation end products (RAGE) and decrease 
in A-disintegrin and metalloprotease (ADAM-10), after 24 hours acrolein induction in HTT22 Cells.

Wang et al. ${ }^{81}$ also found that hippocampal and frontal neurons damage due to stress could be protected by curcumin through cyclic AMP response element binding protein (CREB) and BDNF/TrkB upregulation. Moreover, neurotoxicity induced by nicotine could be protected by curcumin through revival of signal pathway of P-CREB/BDNF, thus, curcumin could reverse the inhibition of brain-derived neurotropic factor (BDNF) and tropomyosin receptor kinase B (TrkB) signaling due to acrolein induction $^{60,83,84}$.

\section{Cardiovascular System}

Cardiovascular diseases are pivotal threats to human health with atherosclerosis, vascular disease and heart disease being among contributing factors. Many researchers have proposed the application of phytochemicals such as curcumin to solve this problem based on its numerous benefits in antioxidant and anti-inflammation mechanisms ${ }^{85}$.

Several research on curcumin showed that atherosclerosis can be alleviated through its anti-inflammatory mechanism against the oxidation of low- density lipoproteins inhibition of thrombocyte aggregation and cholesterol homeostasis modulation. In addition, curcumin supplementation is helpful in lipid peroxidation reduction, low-density lipoprotein-cholesterol (LDL) down-regulation and increasing high-density lipoprotein-cholesterol ${ }^{86-88}$.

In vivo studies revealed that curcumin dietary supplementation in high fat-fed induced atherosclerotic rabbit decreases the levels of triglycerides and cholesterol, as well as inhibiting the oxidation of low density lipoproteins (LDL) ${ }^{88}$. Moreover, atherosclerotic lesions in the aorta such as increased lipid peroxidation and increased oxidative stress in a similar model were showed to be improved by curcumin administration $^{86,88}$.

Similarly, cardiac hypertrophy, fibrosis and inflammation can be protected by curcumin via the inhibition of P300-histone acetyltransferase (HAT), downstream GATA4, NF-kB and further signaling pathways ${ }^{85}$. Curcumin has been widely investigated to suppress excessive manifestation of lipopolysaccharide induced inflammatory mediators in rat vascular smooth muscle cells (VSMCs) by impeding TLR4-MAPK/NF-kB pathways as a result of blocking NADPH-mediated reactive oxygen species (ROS) intracellular production ${ }^{89}$. Moreover, curcumin has been proven to trigger a programed cell death in $\mathrm{H} 9 \mathrm{c} 2$ cells by stimulating the activity of JNKs and increasing reactive oxygen species (ROS) generation ${ }^{85}$.

Curcumin ameliorates hematological parameters, which was indicated in restoring the alterations in white blood cells (WBCs), platelets, fibrinogens, red blood cells (RBCs) count and other hematological indices close to normal in high fat diet (HFD)-fed rats 90 .

\section{Renal System}

Chronic kidney disease (CKD) is associated with continuous loss of renal functions that results in decreased glomerular filtration rate (GFR), abnormalities in urine content such as blood cells and proteins as well as accumulation of uremic toxins due to decreased ability of the kidney to remove soluble waste $^{91}$.

Ali et al. ${ }^{90}$ reported that curcumin reduces creatinine clearance, increases the activity of urinary $\mathrm{N}$-acetyl-B-D-glucosaminidase and uplifts the levels of neutrophil gelatinase-associated lipocalin against adenine-induced chronic kidney disease (CKD) toxicity in a dose dependent pattern in rats.

Curcumin is also shown to attenuate histopathological markers of apoptosis, fibrosis, inflammation, and morphological renal damage, which helps to restore the concentration of plasma sclerostin and bring down the oxidative stress in kidney homogenates ${ }^{92}$. Glomerular hemodynamic changes and oxidative stress seen in $5 / 6$ nephrectomized rats can be reversed by curcumin via the attenuation in proteinuria and restructuring such as mesangial expansion, tubular atrophy, fibrotic glomeruli, and interstitial fibrosis. Importantly, hemodynamic alterations such as oxidative stress, hyperfiltration and glomerular hypertension were reduced by curcumin via increased antioxidant activity and decreased $\mathrm{MDA}^{93}$.

Curcumin can be beneficial in uremia problem and treatment of intestinal dysbiosis, and can improve renal functions and defend the kidney against renal failure by decreasing the expression of mRNA of inflammatory proteins (monocyte chemoattractant protein1) and down-regulating matrix proteins, collagen, TGF-B, and laminin ${ }^{94}$.

\section{CONCLUSIONS AND FUTURE PERSPECTIVES}

Lead-induced toxicity could lead to serious irreversible health implications such as cardiovascular, renal, nervous, and hematopoietic system impairments which causes molecular, cellular, and intracellular alterations in living organisms through apoptosis, ionic mechanism and increased generation of oxidative stress. 


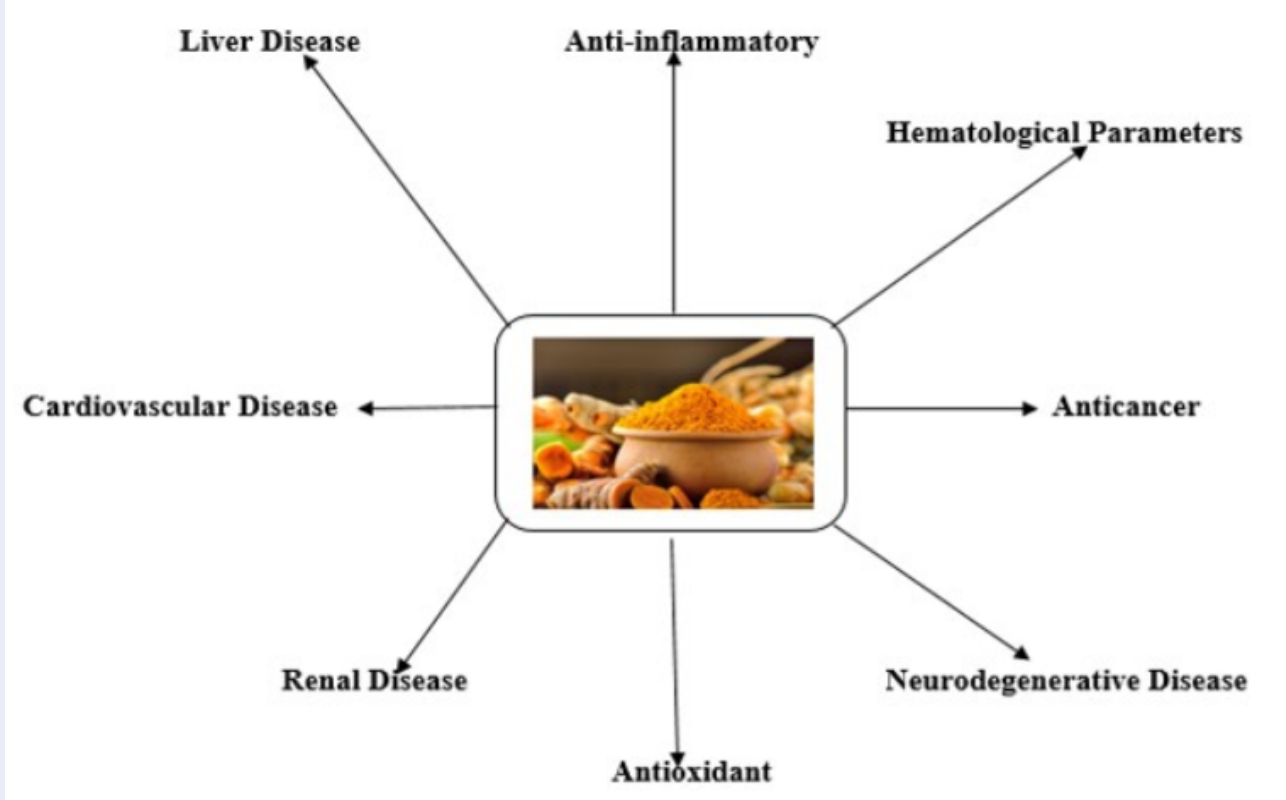

Figure 6: Therapeutic potential of curcumin on various organ-systems.

In consideration to numerous established findings on the therapeutic applications and effects of curcumin on different organ-systems based on its antioxidant, anticancer, and anti-inflammatory mechanism of actions, curcumin could be used both as a protective and therapeutic agent against lead-induced toxicity (Figure 6).

Finally, in correlation to curcumin poor bioavailability, its poor absorption, fast metabolism, and rapid elimination by the gastrointestinal tract, it is recommended that a method of enhancing the bioavailability of curcumin should be carried out for future research.

\section{ABBREVIATIONS}

ALAD: Aminolevulinic acid dehydrates

ALA: Alpha-linolenic acid

BACE-1: Beta-amyloid enzyme 1

CAT: Catalase

CKD: Chronic kidney disease

GSH: Glutathione

HFD: High fat diet

LDL: Low density lipoprotein

MAPK: Mitogen-activated protein kinase

MDA: Malondialdehyde

MCP: Monocytes chemoattractant protein
ROS: Reactive oxygen species

SOD: Super oxide dismutase

STAT 3: Signal transducer and activator of transcription 3

TNF-a: Tumor necrosis factor-alpha

VSMCs: Vascular smooth muscle cells

WBCs: White blood cells

\section{COMPETING INTERESTS}

The authors declare no conflicts of interest.

\section{AUTHORS' CONTRIBUTIONS}

All authors contributed to the drafting of this manuscript. AK and MMM searched, obtained and summarized the data. EAR, $\mathrm{AD}$, and MZA review and edited the first draft of the manuscript. All authors reviewed, commented and approved the final draft of the manuscript.

\section{ACKNOWLEDGMENTS}

The authors would like to acknowledge Universiti Putra Malaysia for funding this research project (Grant number GP-IPS 9663600). The authors will also like to acknowledge the support and effort of Musa Samaila Chiroma throughout the drafting of this manuscript. 


\section{REFERENCES}

1. Flora G, Gupta D, Tiwari A. Toxicity of lead: A review with recent updates. Interdiscip Toxicol. 2012;5(2):47-58. 23118587. Available from: 10.2478/v10102-012-0009-2.

2. Shaffer RM, Gilbert SG. Reducing occupational lead exposures: strengthened standards for a healthy workforce. Neurotoxicology. 2017;69:181-186. 29128313. Available from: 10.1016/j.neuro.2017.10.009.

3. Edwards RL, Luis PB, Varuzza PV, Joseph Al, Presley $\mathrm{SH}$ Chaturvedi $\mathrm{R}$, et al. The anti-inflammatory activity of curcumin is mediated by its oxidative metabolites. J Biol Chem. 2017;292(52):21243-52. 29097552. Available from: 10.1074/ jbc.RA117.000123.

4. Carolina A, Lopes BA, Peixe TS, Mesas AE. Reviews of Environmental Contamination and Toxicology Volume 236. vol. 236. Switzerland AG: Springer Nature; 2016. Available from: http://link.springer.com/10.1007/978-3-319-20013-2.

5. Hewlings SJ, Kalman DS. Curcumin: A Review of Its' Effects on Human Health. Foods. 2017;6(10):92. 29065496. Available from: 10.3390/foods6100092.

6. Ajumobi OO, Tsofo A, Yango M, Aworh MK, Anagbogu IN, Mohammed $A$, et al. High concentration of blood lead levels among young children in Bagega community, ZamfaraNigeria and the potential risk factor. The Pan African Medical Journal. 2014;18(Suppl 1).

7. WHO. Childhood lead poisoning prevention. JAMA J Am Med 2010;89(7):1129-30.

8. Mazumdar M, Bellinger DC, Gregas M, Abanilla K, Bacic J, Needleman HL. Low-level environmental lead exposure in childhood and adult intellectual function: a follow-up study. Environ Heal. 2011;10(1):24. Available from: 10.1186/1476069X-10-24.

9. Needleman $H$. Lead poisoning. Annu Rev Med. 2004;55(1):209-22. 14746518. Available from: 10.1146/annurev.med.55.091902.103653.

10. Dapul H, Laraque D. Lead poisoning in children. Adv Pediatr. 2014;61(1):313-33. 25037135. Available from: 10.1016/j.yapd. 2014.04.004.

11. Gerberding JL, Popovic MDT, Stephens JW, Solomon SL, Bernhardt JM, Director M. Centers for Disease Control and Prevention; 2008.

12. Sanders T, Liu Y, Buchner V, Tchounwou PB. Neurotoxic effects and biomarkers of lead exposure: a review. Rev Environ Health. 2009;24(1):15-45. 19476290. Available from: 10.1515/REVEH.2009.24.1.15.

13. Kosnett MJ, Wedeen RP, Rothenberg SJ, Hipkins KL, Materna $\mathrm{BL}$, Schwartz BS, et al. Recommendations for medical management of adult lead exposure. Environ Health Perspect. 2007;115(3):463-71. 17431500. Available from: 10.1289/ehp. 9784.

14. Chowdhury R, Sarnat SE, Darrow L, McClellan W, Steenland K. Mortality among participants in a lead surveillance program. Environ Res. 2014;132:100-4. 24769120. Available from: 10 . 1016/j.envres.2014.03.008.

15. ATSDR. TOXICOLOGICAL PROFILE FOR LEAD. In: Decision Support Systems; 2007. p. 557-573

16. ATSDR. Lead Toxicity Case Studies in Environmental Medicine. Case Stud Environ Med. 2017;(WB2832):1-182.

17. ATSDR. Agency for Toxic Substances and Disease Registry Case Studies in Environmental Medicine (CSEM) Lead Toxicity. Environ Heal Med Educ. 2015;(WB1105):71.

18. Ekanem AU, Kwari HD, Garba SH, Salami HA. Effect of Lead Acetate on Spleen and Blood Parameters in Albino Rats. IOSR J Dent Med Sci Ver I. 2015;14(3):2279--861.

19. Murata K, Iwata T, Dakeishi M, Karita K. Lead toxicity: does the critical level of lead resulting in adverse effects differ between adults and children? J Occup Health. 2009;51(1):1-12. 18987427. Available from: 10.1539/joh.K8003.

20. Ahijjo YM, Baba-Kutigi AN, Momoh M, Moreh AU. A Review of Sequential Extraction Method for Lead in Samples: A Case Study of Artisanal Mines of Sokoto Basin (Zamfara State).
IJSRST. 2015;2(1):105-9

21. Hassan MM, Nuhu AA, Sallau MS, Majiya HM, Mohammed AK. Zamfara lead poisoning saga\% UNKNOWN UNICODE CHARACTER 0202F (NARROW NO-BREAK SPACE): comparison of lead contamination level of water samples and lead poisoning in Bagega Artisanal gold mining district, Nigeria. J Chem Pharm Res. 2015;7(3):7-12.

22. Holstege CP, Huff JS, Rowden AK, O'Malley RN. Pathophysiology and etiology of lead toxicity. Retrieved from Medscape Web site: http://emedicine medscape com/article/2060369overview. 2013.

23. Papanikolaou NC, Hatzidaki EG, Belivanis S, Tzanakakis GN, Tsatsakis AM. Lead toxicity update. A brief review. Med Sci Monit. 2005;11(10):RA329-36. 16192916.

24. Rabinowitz MB. Toxicokinetics of bone lead. Environ Health Perspect. 1991;91(5):33-7. 2040248. Available from: 10.1289/ ehp. 919133.

25. Jr FB, Tanus-Santos JE, Gerlach RF, Parsons PJ. A critical review of biomarkers used for monitoring human exposure to lead: advantages, limitations, and future needs. Environ Health Perspect. 2005;113(12):1669-74. 16330345. Available from: 10.1289/ehp.7917.

26. Skerfving S, Nilsson U, Schütz A, Gerhardsson L. Biological monitoring of inorganic lead. Scand J Work Environ Health. 1993;19(May):59-64. 8159975.

27. Philip AT. Philip At. Clin Lab Med. 1994;14:84.

28. Shukla V, Shukla P, Tiwari A. Lead poisoning. Indian Journal of Medical Specialities. 2018;9(3):146-149. Available from: https //doi.org/10.1016/j.injms.2018.04.003.

29. Gov AC. Potential for Human Exposure. AtsdrCdcGov. 2008;3:247-308. Available from: http://www.atsdr.cdc.gov/ toxprofiles/tp172-c6.pdf.

30. Brochin R, Leone S, Phillips D, Shepard N, Zisa D, Angerio A The Cellular Effect of Lead Poisoning and Its Clinical Picture. Georg Undergrad J Heal Sci. 2008;5(2):1-8.

31. Samarghandian S, Azimi-Nezhad M, Farkhondeh T, Samini F. Anti-oxidative effects of curcumin on immobilization-induced oxidative stress in rat brain, liver and kidney. Biomed Pharmacother. 2017;87:223-9. 28061405. Available from: 10.1016/j biopha.2016.12.105.

32. Djordjevic J, Djordjevic A, Adzic M, Niciforovic A, Radojcic MB. Chronic Stress Differentially Affects Antioxidant Enzymes and Modifies the Acute Stress Response in Liver of Wistar Rats. 2010;381:729-36.

33. Szymanski M. Molecular mechanisms of lead toxicity. J Biotechnol Comput Biol Bionanotechnol [Internet] 2014:95(2):137-49.

34. Hanas JS, Rodgers JS, Bantle JA, Cheng YG. Lead inhibition of DNA-binding mechanism of Cys(2) His(2) zinc finger proteins. Mol Pharmacol. 1999;56(5):982-8. 10531404. Available from: 10.1124/mol.56.5.982.

35. García-Lestón J, Méndez J, Pásaro E, Laffon B. Genotoxic effects of lead: an updated review. Environ Int. 2010;36(6):62336. 20466424. Available from: 10.1016/j.envint.2010.04.011.

36. Breitenbach $M$, Ralser M, Perrone GG, Iglseder B, Rinnerthaler $M$, Dawes IW. Oxidative stress and neurodegeneration: the yeast model system. Front Biosci. 2013;18(3):1174-93. 23747875. Available from: 10.2741/4171.

37. Flora SJ, Flora G, Saxena G. Environmental occurrence, health effects and management of lead poisoning; 2006. Available from: 10.1016/B978-044452945-9/50004-X.

38. Patrick L. Lead toxicity, a review of the literature. Part 1: Exposure, evaluation, and treatment. Altern Med Rev. 2006;11(1):2-22. 16597190.

39. Lidsky TI, Schneider JS. Lead neurotoxicity in children: basic mechanisms and clinical correlates. Brain. 2003;126(Pt 1):519. 12477693. Available from: $10.1093 / \mathrm{brain} / \mathrm{awg} 014$.

40. Garza A, Vega R, Soto E. Cellular mechanisms of lead neurotoxicity. Med Sci Monit. 2006;12(3):RA57-65. 16501435.

41. Mason LH, Harp JP, Han DY, Mason LH, Harp JP, Han DY. $\mathrm{Pb}$ neurotoxicity: neuropsychological effects of lead toxicity. 
BioMed Res Int. 2014;2014:840547. 24516855. Available from: 10.1155/2014/840547.

42. Rastogi SK. Renal effects of environmental and occupational lead exposure. Indian J Occup Environ Med. 2008;12(3):103-6. 20040966. Available from: 10.4103/0019-5278.44689.

43. Odigie IP, Ladipo CO, Ettarh RR, Izegbu MC. Effect of chronic exposure to low levels of lead on renal function and renal ultrastructure in SD rats. Nigerian Journal of Physiological Sciences. 2004;19(1):27-32.

44. Lin JL, Tan DT, Hsu KH, Yu CC, JaLiang L. Environmental lead exposure and progressive renal insufficiency. Arch Intern Med. 2001;161(2):264-71. 11176742. Available from: 10.1001/archinte.161.2.264.

45. Mao L, Qian Q, Li Q, Wei S, Cao Y, Hao Y, et al. Lead selenide nanoparticles-induced oxidative damage of kidney in rats. Environ Toxicol Pharmacol. 2016;45:63-7. 27262987. Available from: 10.1016/j.etap.2016.05.015.

46. Renner R. Exposure on tap: drinking water as an overlooked source of lead. Environ Health Perspect. 2010;118(2):A68-72. 20123629. Available from: 10.1289/ehp.118-a68.

47. Ambrose TM, Al-Lozi M, Scott MG. Bone lead concentrations assessed by in vivo $\mathrm{X}$-ray fluorescence. Clinical Chemistry. 2000;46(8):1171-1178.

48. Assi MA, Hezmee MN, Haron AW, Sabri MY, Rajion MA. The detrimental effects of lead on human and animal health. Vet World. 2016;9(6):660-71. 27397992. Available from: 10.14202/ vetworld.2016.660-671.

49. Apostoli $\mathrm{P}$, Catalani $\mathrm{S}$. Metal ions affecting reproduction and development. Met lons Life Sci. 2011;8:263-303. 21473384.

50. Lubran MM. Lead toxicity and heme biosynthesis. Ann Clin Lab Sci. 1980;10(5):402-13. 6999974.

51. Schwartz J, Landrigan PJ, Jr ELB, Orenstein WA, von Lindern $\mathrm{IH}$. Lead-induced anemia: dose-response relationships and evidence for a threshold. Am J Public Health. 1990;80(2):1658. 2297059. Available from: 10.2105/AJPH.80.2.165.

52. Alwaleedi SA. Hematobiochemical changes induced by lead intoxication in male and female albinomice. Natl J Physiol Pharm Pharmacol. 2016;6(1):46-51. Available from: 10.5455/ njppp.2015.5.0910201578.

53. TÜRKAY M, TÜRKER H, GÜVEN T. Ultrastructural effects of lead acetate on the spleen of rats. Turk J Biol. 2015;39(3):511-6.

54. Mohiuddin E, Asif M, Sciences A. Curcuma Longa and Curcumin : a Review Article. Plant Biol. 2010;55(2):65-70.

55. Schiborr C, Kocher A, Behnam D, Jandasek J, Toelstede S, Frank J. The oral bioavailability of curcumin from micronized powder and liquid micelles is significantly increased in healthy humans and differs between sexes. Mol Nutr Food Res. 2014;58(3):516-27. 24402825. Available from: $10.1002 / \mathrm{mnfr}$. 201300724.

56. Madhavi D, Kagan D. Bioavailability of a Sustained Release Formulation of Curcumin. Integr Med (Encinitas). 2014;13(3):24-30. 26770097.

57. Mary CP, Vijayakumar S, Shankar R. Metal chelating ability and antioxidant properties of Curcumin-metal complexes - A DFT approach. J Mol Graph Model. 2018;79:1-14. 29127853. Available from: 10.1016/j.jmgm.2017.10.022.

58. Wang YJ, Pan MH, Cheng AL, Lin LI, Ho YS, Hsieh CY, et al. Stability of curcumin in buffer solutions and characterization of its degradation products. J Pharm Biomed Anal. 1997;15(12):1867-76. 9278892. Available from: 10.1016/ S0731-7085(96)02024-9.

59. Basnet P, Skalko-Basnet N. Curcumin: an anti-inflammatory molecule from a curry spice on the path to cancer treatment. Molecules. 2011;16(6):4567-98. 21642934. Available from: 10. 3390/molecules16064567.

60. Shi LY, Zhang L, Li H, Liu TL, Lai JC, Wu ZB. Protective effects of Curcumin on acrolein-induced neurotoxicity in HT22 mouse hippocampal cells. Pharmacol Reports . 2018;70(5):10401046. Available from: 10.1016/j.pharep.2018.05.006.

61. Alisi IO, Uzairu A, Abechi SE, Idris SO. Evaluation of the antioxidant properties of curcumin derivatives by genetic function algorithm. J Adv Res. 2018;12:47-54. 30050693. Available from: 10.1016/.j.jare.2018.03.003.

62. Mahmoud AA, Abdelrahman A, el Aziz HOA. Protective effect of curcumin on the liver of high fat diet-fed rats. Gene Rep. 2018;11(January):18-22. Available from: 10.1016/j.genrep. 2018.01.004

63. Yuan J, Liu W, Zhu H, Zhang X, Feng $Y$, Chen $Y$, et al. Curcumin attenuates blood-brain barrier disruption after subarachnoid hemorrhage in mice. J Surg Res. 2017;207(30):8591. 27979493. Available from: $10.1016 / j$ j.jss.2016.08.090.

64. Baum L, Ng A. Curcumin interaction with copper and iron suggests one possible mechanism of action in Alzheimer's disease animal models. J Alzheimers Dis. 2004;6(4):367-77. 15345806. Available from: 10.3233/JAD-2004-6403.

65. Anand P, Kunnumakkara AB, Newman RA, Aggarwal BB. Bioavailability of curcumin: problems and promises. $\mathrm{Mol}$ Pharm. 2007;4(6):807-18. 17999464. Available from: 10.1021/ mp700113r.

66. Shoba G, Joy D, Joseph T, Majeed M, Rajendran R, Srinivas PS Influence of piperine on the pharmacokinetics of curcumin in animals and human volunteers. Planta Med. 1998;64(4):3536. 9619120 . Available from: $10.1055 / \mathrm{s}-2006-957450$.

67. Jovanovic SV, Steenken S, Boone CW. H-Atom transfer is a preferred antioxidant mechanism of curcumin. . J Am Chem Soc. 1999;121:9677-81. Available from: 10.1021/ja991446m.

68. Priyadarsini KI, Maity DK, Naik GH, Kumar MS, Unnikrishnan MK, Satav JG. Role of phenolic O-H and methylene hydrogen on the free radical reactions and antioxidant activity of curcumin. Free Radic Biol Med. 2003;35(5):475-84. 12927597. Available from: 10.1016/S0891-5849(03)00325-3.

69. Jurenka JS. Anti-inflammatory properties of curcumin, a major constituent of Curcuma longa: a review of preclinical and clinical research. Altern Med Rev. 2009;14(2):141-53. 19594223.

70. Wilken R, Veena MS, Wang MB, Srivatsan ES. Curcumin: A review of anti-cancer properties and therapeutic activity in head and neck squamous cell carcinoma. Mol Cancer. 2011;10(1):12. 21299897. Available from: 10.1186/1476-459810-12.

71. Huang MT, Robertson FM, Lysz T, Ferraro T, Wang ZY, Georgiadis CA. Inhibitory effects of curcumin on carcinogenesis in mouse epidermis. InACS symposium series (USA). 1992;507:338-49.

72. Kohli K, Ali J, Ansari MJ, Raheman Z. Cur cumin : A natural antiinflammatory agent Curcumin. Indian J Pharmacol. 2005;37(3):141-7. Available from: 10.4103/0253-7613.16209.

73. Shehzad A, Lee YS. Molecular mechanisms of curcumin action: signal transduction. Biofactors. 2013;39(1):27-36. 23303697. Available from: 10.1002/biof.1065.

74. Kazazis C, Vallianou NG, Kollas A, Evangelopoulos A. Curcumin and diabetes: mechanisms of action and its anti-diabetic properties. Curr Top Nutraceutical Res. 2014;12(4):135-42.

75. Vallianou NG, Evangelopoulos A, Schizas N, Kazazis C. Curcumin and Sp-1. Anticancer Res. 2015;652(35):645-51. 25667441.

76. Panda AK, Chakraborty D, Sarkar I, Khan T, Sa G. New insights into therapeutic activity and anticancer properties of curcumin. J Exp Pharmacol. 2017;9:31-45. 28435333. Available from: 10.2147/JEP.S70568.

77. Davie JR, He S, Li L, Sekhavat A, Espino P, Drobic B. Nuclear organization and chromatin dynamics1, Sp3 and histone deacetylases. Adv Enzyme Regul. 2008;48(1):189-208. 18187045. Available from: $10.1016 /$ j.advenzreg.2007.11.016.

78. Aoki H, Takada Y, Kondo S, Sawaya R, Aggarwal BB, Kondo Y. Evidence that curcumin suppresses the growth of malignant gliomas in vitro and in vivo through induction of autophagy: role of Akt and extracellular signal-regulated kinase signaling pathways. Mol Pharmacol. 2007;72(1):29-39. 17395690. Available from: $10.1124 / \mathrm{mol} .106 .033167$.

79. Ejaz A, Wu D, Kwan P, Meydani M. Curcumin inhibits adipogenesis in 3T3-L1 adipocytes and angiogenesis and obesity in C57/BL mice. J Nutr. 2009;139(5):919-25. 19297423. Available from: 10.3945/jn.108.100966. 
80. Zhao J, Sun XB, Ye F, Tian WX. Suppression of fatty acid synthase, differentiation and lipid accumulation in adipocytes by curcumin. Mol Cell Biochem. 2011;351(1-2):19-28. 21221723. Available from: 10.1007/s11010-010-0707-z.

81. Um MY, Hwang KH, Ahn J, Ha TY. Curcumin attenuates dietinduced hepatic steatosis by activating AMP-activated protein kinase. Basic Clin Pharmacol Toxicol. 2013;113(3):152-7. 23574662. Available from: 10.1111/bcpt.12076.

82. Weisberg SP, Leibel R, Tortoriello DV. Dietary curcumin significantly improves obesity-associated inflammation and diabetes in mouse models of diabesity. Endocrinology. 2008;149(7):3549-58. 18403477. Available from: 10.1210/en. 2008-0262.

83. Wang R, Li YH, Xu Y, Li YB, Wu HL, Guo H, et al. Curcumin produces neuroprotective effects via activating brainderived neurotrophic factor/TrkB-dependent MAPK and PI-3K cascades in rodent cortical neurons. Prog Neuropsychopharmacol Biol Psychiatry. 2010;34(1):147-53. 19879308. Available from: 10.1016/j.pnpbp.2009.10.016.

84. Motaghinejad M, Motevalian M, Fatima S, Faraji F, Mozaffari S. The Neuroprotective Effect of Curcumin Against NicotineInduced Neurotoxicity is Mediated by CREB-BDNF Signaling Pathway. Neurochem Res. 2017;42(10):2921-32. 28608236. Available from: 10.1007/s11064-017-2323-8.

85. He Y, Yue Y, Zheng X, Zhang K, Chen S, Du Z. Curcumin, inflammation, and chronic diseases: how are they linked? Molecules. 2015;20(5):9183-213. 26007179. Available from: 10.3390/molecules20059183.

86. Kapakos G, Youreva V, Srivastava AK. Cardiovascular protection by curcumin: molecular aspects. Indian J Biochem Biophys. 2012;49(5):306-15. 23259317

87. Li X, Lu Y, Sun Y, Zhang Q. Effect of curcumin on permeability of coronary artery and expression of related proteins in rat coronary atherosclerosis heart disease model. International journal of clinical and experimental pathology.
2015;8(6):7247.

88. Ramírez-Tortosa MC, Mesa MD, Aguilera MC, Quiles JL, Baró L, Ramirez-Tortosa CL. Oral administration of a turmeric extract inhibits LDL oxidation and has hypocholesterolemic effects in rabbits with experimental atherosclerosis. Atherosclerosis. 1999:147(2):371-8. 10559523. Available from: 10.1016/ S0021-9150(99)00207-5.

89. Meng Z, Yan C, Deng Q, Gao DF, Niu XL. Curcumin inhibits LPS-induced inflammation in rat vascular smooth muscle cells in vitro via ROS-relative TLR4-MAPK/NF- $\kappa$ B pathways. Acta Pharmacol Sin. 2013;34(7):901-11. 23645013. Available from: 10.1038/aps.2013.24.

90. El-Habibi EM, El-Wakf AM, Mogall A. Efficacy of curcumin in reducing risk of cardiovascular disease in high fat diet-fed rats. Journal of Bioanalysis and Biomedicine. 2013;5:66-70.

91. Ghosh SS, Gehr TW, Ghosh S. Curcumin and chronic kidney disease (CKD): major mode of action through stimulating endogenous intestinal alkaline phosphatase. Molecules. 2014;19(12):20139-56. 25474287. Available from: 10.3390/ molecules191220139.

92. Ali BH, Al-Salam S, Suleimani YA, Kalbani JA, Bahlani SA, Ashique $M$, et al. Curcumin Ameliorates Kidney Function and Oxidative Stress in Experimental Chronic Kidney Disease. Basic Clin Pharmacol Toxicol. 2018;122(1):65-73. 28561324 Available from: $10.1111 /$ bcpt.12817.

93. Tapia E, Soto V, Ortiz-Vega KM, Zarco-Márquez G, Molina-Jijón E, Cristóbal-García M, et al. Curcumin induces Nrf2 nuclear translocation and prevents glomerular hypertension, hyperfiltration, oxidant stress, and the decrease in antioxidant enzymes in 5/6 nephrectomized rats. Oxidative medicine and cellular longevity. 2012;2012

94. de Almeida Alvarenga L. Curcumin - A promising nutritional strategy for chronic kidney disease patients. J Funct Foods. 2017;2018(40):715-21. Available from: 10.1016/j.jff.2017.12. 015. 